\title{
PAPER
}

\section{Incidence (1988-97) and prevalence (1997) of multiple sclerosis in Västerbotten County in northern Sweden}

\author{
P Sundström, L Nyström, L Forsgren
}

J Neurol Neurosurg Psychiatry 2003;74:29-32

See end of article for
authors' affiliations
$\ldots \ldots \ldots \ldots \ldots \ldots \ldots \ldots \ldots$
Correspondence to:
Dr Peter Sundström,
Department of Neurology,
Umeå University Hospital,
S-901 85 Umeå, Sweden;
peter.sundstrom@
neuro.umu.se
Received 16 May 2002
In revised form 23
September 2002
Accepted 23 September
2002
Objective: To investigate the incidence and prevalence of multiple sclerosis in Västerbotten County in northern Sweden.

Methods: Multiple sources were used in the case identification process. Follow up interviews with clinical examinations were undertaken and, when indicated, additional paraclinical investigations were done. In this way case ascertainment was assured and supplemental clinical data were collected. The incidence rate was based on symptom onset. Onset adjusted prevalence was applied.

Results: The crude incidence rate of multiple sclerosis in 1988-97 in Västerbotten County was 5.2/ $10^{5}(95 \%$ confidence interval, 4.4 to 6.2$): 6.7 / 10^{5}(6.0$ to 8.3$)$ in women and $3.7 / 10^{5}$ (2.7 to 4.9$)$ in men. The onset adjusted prevalence for 31 December 1997 was 154/105 (139 to 170): 202/10 (179 to 228 ) in women and $105 / 10^{5}$ (89 to 125$)$ in men. When compared with a previous estimate of prevalence, a yearly $2.6 \%$ increase in prevalence between 1990 and 1997 was found, mainly attributable to a higher incidence than mortality.

Conclusions: The present incidence rate and prevalence confirms earlier findings that Västerbotten is a high risk area for multiple sclerosis. The adjusted incidence was twice as high as the incidence from 1974-88 in the only previous Swedish population based study from Göteborg, but comparable with other recent Fennoscandian multiple sclerosis incidence rates.
G eographical variation in multiple sclerosis occurrence has challenged researchers since the beginning of the 20th century. ${ }^{1}$ Incidence data from different areas in Scandinavia are available and have been compared. ${ }^{2}$ Population based studies of multiple sclerosis incidence in Sweden have previously only been done in Göteborg in south west Sweden. ${ }^{3}$ Our aim in this study was to investigate multiple sclerosis incidence and prevalence in Västerbotten County in northern Sweden-using multiple sources for case identification and follow up interviews, together with medical records for data collection and case ascertainment-and to provide a base for further follow up studies.

\section{METHODS}

Västerbotten County is located in northern Sweden at $64-65^{\circ} \mathrm{N}$ latitude. It is sparsely populated with 255987 inhabitants at the midpoint of the incidence period 1988-97, and 259163 on the prevalence day, 31 December 1997, in an area of $55432 \mathrm{~km}^{2}$.

The database used in a previous study, with the prevalence day 1 January $1990,{ }^{4}$ was extended using the same multiple sources. A computerised data register search from all three hospitals in Västerbotten County was extended through year 2000. Inpatients were selected from the neurology (also outpatients), neurosurgery, neurorehabilitation, internal medicine, ophthalmology, paediatric, and geriatric clinics with ICD codes corresponding to the following diagnoses: multiple sclerosis, demyelinating disorders in CNS, optic neuritis, spastic paraplegia, ataxia, myelopathy, spinocerebellar disease, and myelitis. In addition we used six other sources:

- Register for CSF electrophoresis analyses 1988-2000: analyses with presence of oligoclonal bands or signs of intrathecal IgG production were recorded.

- General practitioners, 1988-98: in April 1998 all general practitioners were contacted by letter; we asked for information on patients with multiple sclerosis or inflammatory disorder of the central nervous system for the past 10 year period.
- District head nurses, 1988-98: in April 1998 every district head nurse responsible for nursing homes was contacted and asked to consult their nurses with the same request as for general practitioners.

- Hereditary cases, 1997-2001: during the follow up interview patients were asked about relatives with multiple sclerosis.

- Clinical cases, 1997-2001: cases identified at the clinic by us.

- The cause of death registry, 1990-99: the Swedish cause of death registry has been computerised since 1961; we selected all cases with multiple sclerosis or inflammatory disease of the central nervous system as the underlying or contributory cause of death for individuals who died in the county of Västerbotten in 1990-99.

For every individual identified from the sources it was possible to collect information enabling a decision to be made on whether the patient had multiple sclerosis or not. Individuals with a diagnosis of multiple sclerosis and those with medical records indicating multifocal symptoms possibly caused by multiple sclerosis were contacted by letter.

\section{Case definition}

A list of symptoms was used to define disease onset. ${ }^{5}$ Incident cases had experienced an onset symptom in agreement with the definition when residing in the study area any time from I January 1988 to 31 December 1997 and were later judged to fulfil the Poser diagnostic criteria. ${ }^{6}$ Prevalent cases had experienced an onset symptom in agreement with the definition before the prevalence day, were resident in the study area on the prevalence day, and fulfilled the Poser criteria at the time for data collection-that is, onset adjusted prevalence.

\section{Case ascertainment}

From August 1997 to December 2001, we did follow up interviews and examinations on people willing to participate. For most individuals the study nurse did part of the interview, 
Table 1 Annual incidence 1988-97 and prevalence on 31 December 1997 of multiple sclerosis in Västerbotten County per 100000 population by age and sex

\begin{tabular}{|c|c|c|c|c|c|c|c|c|c|c|c|c|}
\hline \multirow{3}{*}{$\begin{array}{l}\begin{array}{l}\text { Age group } \\
\text { (years) }\end{array} \\
0 \text { to } 14\end{array}$} & \multicolumn{6}{|c|}{ Incidence (number of cases) } & \multicolumn{6}{|c|}{ Prevalence (number of cases) } \\
\hline & \multicolumn{2}{|c|}{ Female } & \multicolumn{2}{|c|}{ Male } & \multicolumn{2}{|c|}{ Total } & \multicolumn{2}{|c|}{ Female } & \multicolumn{2}{|c|}{ Male } & \multicolumn{2}{|c|}{ Total } \\
\hline & 0.4 & (1) & 0.4 & (1) & 0.4 & (2) & 0 & & 0 & & 0 & \\
\hline 15 to 24 & 8.4 & (14) & 2.9 & (5) & 5.6 & (19) & 34 & (6) & 17 & (3) & 26 & (9) \\
\hline 25 to 34 & 19.2 & (32) & 10.0 & (18) & 14.4 & (50) & 185 & (31) & 110 & (20) & 146 & (51) \\
\hline 35 to 44 & 13.4 & (23) & 8.7 & (16) & 10.9 & (39) & 408 & (67) & 181 & (31) & 292 & (98) \\
\hline 45 to 54 & 7.5 & (12) & 4.2 & (7) & 5.9 & (19) & 402 & (69) & 206 & (38) & 300 & (107) \\
\hline 55 to 64 & 3.1 & (4) & 0 & & 1.6 & (4) & 340 & (45) & 146 & (19) & 244 & (64) \\
\hline 65 to 74 & 0 & & 0 & & 0 & & 249 & (31) & 194 & (21) & 223 & (52) \\
\hline $75+$ & 0 & & 0 & & 0 & & 113 & (14) & 48 & (4) & 87 & (18) \\
\hline Total & 6.7 & (86) & 3.7 & (47) & 5.2 & (133) & 202 & (263) & 105 & (136) & 154 & (399) \\
\hline $95 \% \mathrm{Cl}$ & \multicolumn{2}{|c|}{6.0 to 8.3} & \multicolumn{2}{|c|}{2.7 to 4.9} & \multicolumn{2}{|c|}{4.4 to 6.2} & \multicolumn{2}{|c|}{179 to 228} & \multicolumn{2}{|c|}{89 to 125} & \multicolumn{2}{|c|}{139 to 170} \\
\hline
\end{tabular}

$\mathrm{Cl}$, confidence interval.

either during the visit or by telephone. The purpose was to confirm or refute a diagnosis of multiple sclerosis and to collect additional data. The result of magnetic resonance imaging (MRI), cerebrospinal fluid (CSF) analyses, evoked potentials, and relevant laboratory tests were recorded. If clinically indicated, new examinations were performed.

The local ethics committee approved the study.

\section{Statistical methods}

For statistical calculations, SPSS 10.0 was used. Standardisation was calculated by the direct method. The Poisson distribution was used for $95 \%$ confidence intervals (CI), and Student's $t$ test to test for differences between arithmetical means. To test whether or not the differences between the person-time incidence rates in the Västerbotten and the Göteborg cohorts were a result of random variation, the exact binomial test was used.

\section{RESULTS}

Diagnostic registers identified $91 \%$ of incident and $92 \%$ of prevalent cases. The remaining incident and prevalent cases were found in CSF registers $(3 \%, 2 \%)$ or general practices $(0 \%$,

Table 2 Case ascertainment in the incidence and prevalence population

\begin{tabular}{llllll}
\hline & \multicolumn{2}{l}{ Incidence } & & \multicolumn{2}{l}{ Prevalence } \\
\cline { 2 - 3 } \cline { 5 - 6 } & $\mathrm{n}$ & $\%$ & & $\mathrm{n}$ & $\%$ \\
\hline No of cases & 133 & & & 399 & \\
Follow up interview & 123 & 95 & & 364 & 91 \\
Follow up examination & 95 & 71 & & 324 & 81 \\
MRI supporting diagnosis* & 117 & 94 & & 262 & 93 \\
CSF immunopathy & 122 & 95 & & 313 & 84 \\
Both MRI and CSF negative & 1 & 1 & & 3 & 1 \\
\hline
\end{tabular}

*From medical records. For MRI and CSF percentages refers to cases investigated.

CSF, cerebrospinal fluid; MRI, magnetic resonance imaging

Table 3 Diagnostic classification

\begin{tabular}{llllll}
\hline & \multicolumn{2}{l}{ Incidence } & & \multicolumn{2}{l}{ Prevalence } \\
\cline { 2 - 3 } \cline { 6 - 7 } Poser criteria & $\mathrm{n}$ & $\%$ & & $\mathrm{n}$ & $\%$ \\
\hline Clinically definite & 116 & 87 & & 369 & 92 \\
Laboratory supported definite & 15 & 11 & & 19 & 5 \\
$\begin{array}{l}\text { Clinically probable } \\
\text { Laboratory supported probable }\end{array}$ & 2 & 2 & & 6 & 2 \\
Not classified & 0 & & & 2 & 0 \\
Total & 133 & 100 & & 399 & 100 \\
\hline
\end{tabular}

$1 \%)$, or were hereditary $(1 \%, 1 \%)$ or clinical cases $(5 \%, 4 \%)$. The cause of death register and district head nurses did not identify any case not found by the other sources.

\section{Incidence}

In all, 133 cases had their onset of multiple sclerosis during 1988-97. The crude incidence rate was $5.2 / 10^{5}$ (95\% CI, 4.4 to $6.2)$ : $6.7 / 10^{5}$ (6.0 to 8.3$)$ in women and $3.7 / 10^{5}(2.7$ to 4.9$)$ in men (table 1). Thus the female to male ratio was 1.8 .

Diagnosis was ascertained through follow up interviews and the results of paraclinical investigations (table 2), resulting in a distribution of diagnostic categories classified shown in table 3. At the time of follow up, one subject had died and 10 had moved from the study area.

\section{Prevalence}

The onset adjusted prevalence of multiple sclerosis in Västerbotten County on 31 December 1997 was 399 cases in a population of 259163 , giving a crude prevalence of 154/10 $(95 \%$ CI, 139 to 170 ) (table 1 ). The prevalence in women was $202 / 10^{5}$ ( 179 to 228 ) and in men, $105 / 10^{5}$ ( 89 to 125 ), resulting in a female to male ratio of 1.9. The mean age was 49 years (range 18 to 86$)$.

The prevalence in 1990 with follow up to the end of 1997 was estimated at $125 / 10^{5}(\mathrm{n}=313)$ and increased to $131 / 10^{5}$ (95\% CI, 118 to $146 ; n=328$ ) when follow up was extended through 2001 (fig 1). The prevalence in 1997 with follow up through 2001 was estimated at $154 / 10^{5}(\mathrm{n}=399)$. The yearly increase of $2.6 \%$ was mainly the result of a greater number of incident cases $(n=105)$ than of deceased cases $(n=40)$.

\section{DISCUSSION}

The levels of incidence and prevalence in our study confirm earlier findings ${ }^{4}$ that Västerbotten is a high risk area for multiple sclerosis. The increase in prevalence between 1990 and 1997 is explained by a lower mortality than incidence over that period. The yearly $2.6 \%$ increase in prevalence probably reflects a lower mortality caused by improved survival. However, an increase in incidence cannot be excluded.

The methodology (for example, sources used for case identification and length of follow up) affects estimates of incidence and prevalence. Here the source of $3 \%$ of the incident cases was the results of CSF electrophoresis analyses, and it is likely that more cases would have been identified if the results of MRI and evoked potentials had been scrutinised. In this study, the extension of follow up from 1998 through 2001 enabled the identification of another 16 prevalent cases in 1990, thereby increasing the number of cases by $5 \%$.

The only previous Swedish population based incidence study is from Göteborg. The crude incidence in Göteborg was $4.2 / 10^{5}$ in $1950-64$ and $2.6 / 10^{5}$ in $1974-88$ (estimated by us). To enable comparison, we excluded cases in our study where 


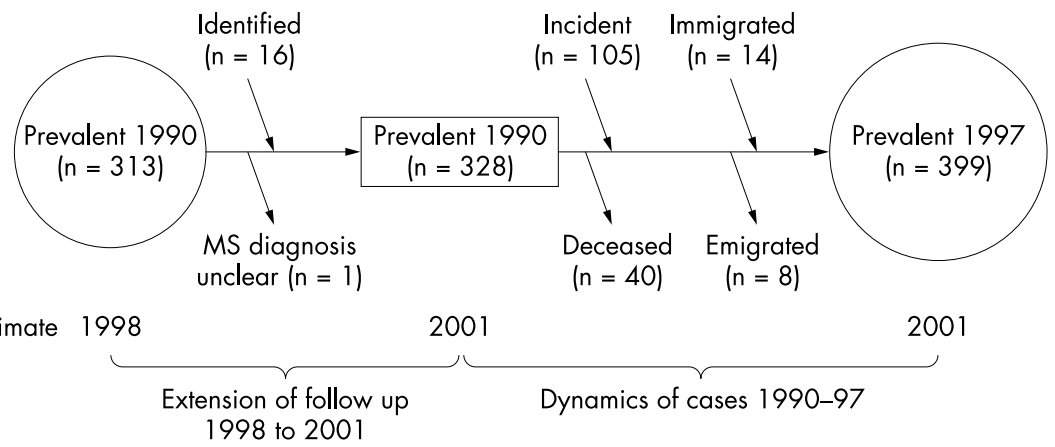

Figure 1 Flow chart illustrating the data generation of prevalent cases.

\begin{tabular}{|c|c|c|c|c|c|c|c|c|}
\hline Country & Area & Year & $\begin{array}{l}\text { Crude incidence } \\
\text { (CI) }\end{array}$ & $\begin{array}{l}\text { Number } \\
\text { of cases }\end{array}$ & $\begin{array}{l}\text { Latitude } \\
\left({ }^{\circ} \mathrm{N}\right)\end{array}$ & Diagnosticcriteria & $\begin{array}{l}\text { Data collection } \\
\text { until }\end{array}$ & Reference \\
\hline \multirow[t]{6}{*}{ Norway } & Vestfold & $\begin{array}{l}1973 \text { to } 1977 \\
1978 \text { to } 1982\end{array}$ & $\begin{array}{l}3.5 \\
2.1\end{array}$ & $\begin{array}{l}32 \\
20\end{array}$ & 60 & McAlpine; definitive/probable & January 1983 & 7 \\
\hline & Troms and Finnmark & $\begin{array}{l}1974 \text { to } 1978 \\
1979 \text { to } 1983 \\
1984 \text { to } 1988 \\
1989 \text { to } 1992\end{array}$ & $\begin{array}{ll}2.6 & (1.7 \text { to } 3.7) \\
3.0 & (2.1 \text { to } 4.2) \\
3.5 & (2.5 \text { to } 4.8) \\
4.3 & (3.0 \text { to } 5.9)\end{array}$ & $\begin{array}{l}29 \\
33 \\
39 \\
38\end{array}$ & $\geqslant 68$ & Poser; definite/probable & 1995 & 8 \\
\hline & More and Romsdal & $\begin{array}{l}1975 \text { to } 1979 \\
1980 \text { to } 1984 \\
1985 \text { to } 1991\end{array}$ & $\begin{array}{ll}5.2 & (2.8 \text { to } 9.4) \\
5.7 & (3.2 \text { to } 9.9) \\
4.0 & (2.0 \text { to } 7.7)\end{array}$ & $\begin{array}{l}60 \\
67 \\
66\end{array}$ & 63 & McAlpine; definitive/probable & August 1992 & 9 \\
\hline & Hordaland & 1973 to 1977 & $4.1(2.1 \text { to } 6.1)^{*}$ & 80 & $\begin{array}{l}59 \text { to } \\
61\end{array}$ & McAlpine; incl possible & $1988 ?$ & 10 \\
\hline & & $\begin{array}{l}1978 \text { to } 1982 \\
1983 \text { to } 1987\end{array}$ & $\begin{array}{l}4.7(2.4 \text { to } 7.0)^{*} \\
3.2(0.6 \text { to } 5.8)^{*}\end{array}$ & $\begin{array}{l}92 \\
64\end{array}$ & & & & \\
\hline & Oslo & $\begin{array}{l}1972 \text { to } 1976 \\
1977 \text { to } 1981 \\
1982 \text { to } 1986 \\
1987 \text { to } 1991 \\
1992 \text { to } 1996\end{array}$ & $\begin{array}{ll}3.6 & (2.2 \text { to } 6.0) \\
4.4 & (2.8 \text { to } 6.9) \\
4.9 & (3.1 \text { to } 7.6) \\
7.2 & (5.0 \text { to } 10.2) \\
8.7 & (6.3 \text { to } 11.9)\end{array}$ & $\begin{array}{l}87 \\
101 \\
109 \\
164 \\
210\end{array}$ & 59 & Poser; definite & December 1999 & 11 \\
\hline Denmark & Denmark & $\begin{array}{l}1970 \text { to } 1979 \\
1980 \text { to } 1989\end{array}$ & $\begin{array}{l}4.1 \quad(3.9 \text { to } 4.3) \\
5.0(4.8 \text { to } 5.2)\end{array}$ & $\begin{array}{l}- \\
-\end{array}$ & $\begin{array}{l}52 \text { to } \\
57\end{array}$ & $\begin{array}{l}\text { Allison and Millar; incl possible } \\
\text { before 1994, then Poser }\end{array}$ & January 1994 & 12 \\
\hline Finland & $\begin{array}{l}\text { Vaasa } \\
\text { Seinäjoki }\end{array}$ & $\begin{array}{l}1979 \text { to } 1993 \\
1979 \text { to } 1993 \\
1979 \text { to } 1993\end{array}$ & $\begin{array}{l}5.2(4.1 \text { to } 6.3) \\
11.6 \\
(10.1 \text { to } 13.8) \\
51(4.8 \text { ) } 5.5)\end{array}$ & $\begin{array}{l}90 \\
240\end{array}$ & $\begin{array}{l}63 \\
63\end{array}$ & Poser; definite & December 1993 & 13 \\
\hline Sweden & $\begin{array}{l}\text { Göteborg } \\
\text { Västerbotten }\end{array}$ & $\begin{array}{l}1974 \text { to } 1988 \\
1988 \text { to } 1997\end{array}$ & $\begin{array}{l}2.6(2.2 \text { to } 3.0) \dagger \\
5.2(4.4 \text { to } 6.2)\end{array}$ & $\begin{array}{l}166 \\
133\end{array}$ & $\begin{array}{l}57 \\
64 \text { to } \\
65\end{array}$ & $\begin{array}{l}\text { Poser; definite/probable } \\
\text { Poser; definite/probable }\end{array}$ & $\begin{array}{l}1988 \\
2001\end{array}$ & $\begin{array}{l}3 \\
\text { Present }\end{array}$ \\
\hline
\end{tabular}

paraclinical evidence was used for categorisation $(\mathrm{n}=4)$. The age and sex adjusted incidence was $5.4 / 10^{5}$ and $5.3 / 10^{5}$, respectively, for the two study periods, both being significantly higher in the present study $(\mathrm{p}=0.017$ and $\mathrm{p}<0.001$ ).

Fennoscandian incidence studies on multiple sclerosis during 25 years are summarised in table 4 . An optimal comparison would require identical sources of case identification, organisation of health services, diagnostic criteria, and use of paraclinical diagnostic tools.

Figure 2 illustrates the incidence of multiple sclerosis in Scandinavia and Finland over time. Each setting with more than one estimate during the study period is presented as a line; however, in three studies ${ }^{7810}$ the last observation had to be ignored as the end of data collection and the last five year period coincided, thus causing an underestimation of the true incidence. Further, the rates in the Finnish study were corrected for using the population aged 10-70 years as denominator. The pattern indicates an increase in the incidence, in particular at the end of the period. However, this interpretation has to be accepted with caution and more estimates are required from each setting to facilitate a statistical analysis.

The Finnish study ${ }^{13}$ shows very high incidence figures for the Seinäjoki area, which had been separated from the larger Vaasa area used in previous studies. The incidence rates were calculated as mentioned above. The incidence in the present study increased from $5.2 / 10^{5}$ to $7.0 / 10^{5}$ using the corresponding denominator.

The Oslo study ${ }^{11}$ has the second highest incidence and, as in the Finnish study, used the year of diagnosis. The year of onset was used in the other studies. For 1988-97, the number of cases $(n=141)$ resident in the study area receiving a diagnosis of multiple sclerosis or CNS demyelinating disorder exceeded the number of cases in the incidence cohort, even 


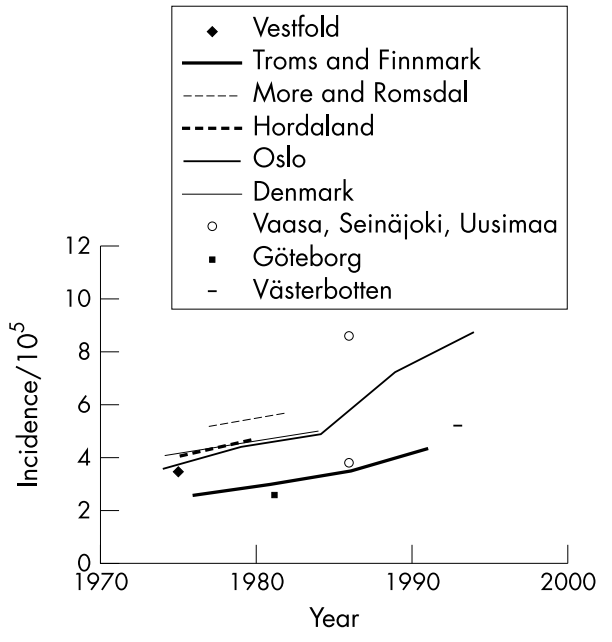

Figure 2 Incidence of multiple sclerosis over time in Scandinavia and Finland over the past 25 years.

when just searching through the present prevalence and incidence population cases. Apart from being less biologically relevant, the year of diagnosis could harbour bias overestimating incidence, even when time to diagnosis is stable. This would be the case if individuals tend to move into the study area between onset and diagnosis. When corrected for methodology, some differences in crude incidence rates between Fennoscandian areas can certainly be reduced.

\section{Conclusions}

This study, using multiple sources for case identification and follow up interview and examination for case ascertainment, shows a prevalence of $154 / 10^{5}(95 \%$ CI, 139 to 170$)$ and an incidence rate of $5.2 / 10^{5}$ (4.4 to 6.2), thereby confirming that Västerbotten is a high risk area for multiple sclerosis. The incidence in Västerbotten county in 1988-97 was twice as high as in Göteborg in 1974-88, but comparable with rates from most other recent Fennoscandian studies.

\section{Authors' affiliations}

P Sundström, L Forsgren, Department of Neurology, Umeå University Hospital, Umeå, Sweden

L Nyström, Department of Epidemiology and Public Health, Umeå University Hospital

Competing interests: none declared

\section{REFERENCES}

1 Davenport CB. Multiple sclerosis from the standpoint of geographic distribution and race. Arch Neurol 1922;8:51-60.

2 Koch-Henriksen NJ. Multiple sclerosis in Scandinavia and Finland. Acta Neurol Scand Suppl 1995;161:55-9.

3 Svenningsson A, Runmarker B, Lycke J, et al. Incidence of MS during two fifteen-year periods in the Gothenburg region in Sweden. Acta Neurol Scand 1990;82:161-8.

4 Sundström P, Nyström L, Forsgren L. Prevalence of multiple sclerosis in Västerbotten County in Northern Sweden. Acta Neurol Scand 2001;103:214-18.

5 Poser CM. Onset symptoms of multiple sclerosis [letter]. J Neurol Neurosurg Psychiatry 1995;58:253-4.

6 Poser CM, Paty DW, Scheinberg L, et al. New diagnostic criteria for multiple sclerosis: guidelines for research protocols. Ann Neurol 1983; 13:227-31.

7 Edland A, Nyland $\mathrm{H}$, Riise T, et al. Epidemiology of multiple sclerosis in the county of Vestfold, eastern Norway: incidence and prevalence calculations. Acta Neurol Scand 1996;93:104-9.

8 Groenlie SA, Myrvoll E, Hansen G, et al. Multiple sclerosis in North Norway and first appearance in an indigenous population. J Neurol 2000;247: 129-33.

9 Midgard R, Riise T, Svanes C, et al. Incidence of multiple sclerosis in Moere and Romsdal, Norway from 1950 to 1991. Brain 1996; 1 19:203-11.

10 Groenning M, Riise T, Kvåle G, et al. Incidence of multiple sclerosis in Hordaland, Western Norway: a fluctuating pattern. Neuroepidemiology $1991 ; 10: 53-61$

11 Celius EG, Vandvik B. Multiple sclerosis in Oslo, Norway: prevalence on 1 January 1995 and incidence over a 25 -year period. Eur J Neurol 2001;8:463-9.

12 Koch-Henriksen N. The Danish Multiple Sclerosis Registry: a 50-year follow-up. Mult Scler 1999;5:293-6.

13 Sumelahti ML, Tienari PJ, Wikström J, et al. Regional and temporal variation in the incidence of multiple sclerosis in Finland 1979-1993. Neuroepidemiology 2000;19:67-75. 